\title{
The determination of hydraulic resistance during laminar filtration through layers of sorbents and ion-exchange granules in environmental mass exchange equipment
}

\author{
Nikolay Merentsov ${ }^{1, *}$, Alexander Balashov ${ }^{1}$, Alexander Golovanchikov ${ }^{1}$ and Mikhail \\ Topilin ${ }^{2}$ \\ ${ }^{1}$ Volgograd State Technical University, 400005 Volgograd, Russia \\ ${ }^{2}$ Branch of LUKOIL-Engineering VolgogradNIPImorneft, 400078 Volgograd, Russia
}

\begin{abstract}
The paper presents main calculation dependencies, their advantages and disadvantages for calculating the hydraulic resistance of granular and porous layers in the area of low filtration rates. Approaches are given to account for the influence of porosity and size of particles (sorbent granules) that differ in the values of constants and different ways to account for the influence of particle shape on the hydraulic resistance of the granular layer.
\end{abstract}

\section{Introduction}

Filtration flows are used in many industrial processes and products of various branches of mechanical engineering, in technologies and equipment of the chemical industry and related industries [1-17]. Filtration is used in water treatment processes and in environmental technologies [18-41]. Filtration processes are an integral part of the hydrology and technologies of oil and gas production [42, 43]. Filtration flows are also implemented in a wide range of environmental mass transfer equipment, in such processes as adsorption, desorption, ion exchange, etc. [44-73].

The hydraulic resistance of the porous layer is an important technical characteristic of devices that operate using filtration flows (adsorption, ion exchange, drying, filtration, flow of gas and liquid-phase reaction products through the porous layers of the catalyst, etc.). The main purpose is determination the hydraulic resistance of a porous layer, so it is necessary to have equations approximating the filtration curve as a dependence of the pressure gradient on the filtration rate $\Delta P / H=f\left(v_{f}\right)$, or criterion equations for determining the coefficient of hydraulic resistance of a granular layer, followed by determining its hydraulic resistance using the modified Darcy-Weisbach equation for filtration flow in a porous layer.

Usually, when you are performing engineering calculations, it is necessary to determine the hydraulic resistance of the porous layer in a limited range of possible changes in the filtration rate. This range of filtration rate can be located in the area of a linear section of

\footnotetext{
* Corresponding author: steeple@mail.ru
} 
the filtration curve, within its nonlinear section, or at the same time partially belong to the linear and nonlinear sections in the area of their interface.

\section{Methods and materials}

Let's consider the determination of the hydraulic resistance of a porous layer for the area of a linear section of the filtration curve using approximating dependencies. The mode of filtration flow within a linear section of the filtration curve is usually called laminar filtration. This mode of filtration flow is found, for example, in such processes as adsorption, ion exchange processes, fine cleaning of liquids using thin-pore volumetric filter partitions, etc.

The approximating equation is the dependence where $k$ is the permeability of the porous layer and $\mu$ is the viscosity of the liquid for a linear section of the filtration curve (for laminar filtration) based on Darcy's law

$$
\frac{\Delta P}{H}=\frac{1}{k} \mu v_{f}
$$

It is necessary to Express the parameters that characterize the structure of the porous layer to use this dependence in the calculation practice. The variety of structures of the porous layer also generates the existence of different forms of this equation. The dependencies expressed in terms of the structural parameters of the porous layer are known as the Kozeny-Carman equations. In the field of chemical technology, the Kozeny-Carman equations for granular porous media obtained using a capillary model of the structure of a porous material have become widespread.

The widely used Kozeny-Carman equation for a granular layer is known, obtained in the framework of the capillary model, when the flow of liquid in the channels of the model is considered by analogy with the Darcy-Weisbach equation [74]

$$
\frac{\Delta P}{H}=150 \frac{(1-\varepsilon)^{2}}{\phi^{2} \varepsilon^{3} d^{2}} \mu v_{f},
$$

where $\varepsilon$ is the porosity of the layer, $d=d_{\text {sphere }}$ is used for a layer of spherical particles and $d_{\text {e.d. }}$ is the equivalent diameter of particles whose shape is different from the ball. A $d_{\text {e.d. }}$ is the diameter of such a spherical particle is assumed, the volume of which is equal to the volume of a particle of irregular shape; $\phi$ - the shape factor, usually called the shape coefficient. The coefficient "150" included in formula (2) is called the Kozeny - Carman constant. However, the value of this coefficient is not constant and can vary from "150" to "200 " [75]. One of the reasons for its low values may be an incorrect estimate of the shape factor (coefficient), which is defined as the ratio of the surface of the ball, which is equal in volume to the particle, to the surface of this particle. Its value, as you can see, is not difficult to calculate for particles of any shape. And differences of different authors on the estimation of the value of the form factor (coefficient) in determining the hydraulic resistance of a granular layer made of the same material can cause discrepancies in the calculation results at the assumed constant value of the Kozeny - Carman constant.

In the paper [76], the flow in the channels of the capillary model is considered by analogy with the Poiseuille equation. The resulting dependence is a generalized KozenyCarman equation that is valid for filtration flow in any type of porous layer, regardless of its internal structure

$$
\frac{\Delta P}{H}=K \frac{\sigma^{2}}{\varepsilon^{3}} \mu v_{f},
$$


where $K$ is the Kozeny-Carman constant, $\sigma$ is the specific surface area of the porous layer, related to the unit of its volume. Expressing in this equation the specific surface of a granular layer in terms of its particle diameter and porosity as

$$
\sigma=\frac{6}{d(1-\varepsilon)},
$$

the Kozeni-Karman equation for a granular layer is obtained as a dependence

$$
\frac{\Delta P}{H}=K \frac{36(1-\varepsilon)^{2}}{\varepsilon^{3} d^{2}} \mu v_{f},
$$

where, as in the equation (2), $d=d_{\text {sphere }}$ is used for a layer of spherical particles and $d_{\text {e.d. }}$ is the equivalent diameter of particles whose shape is different from the ball.

As can be seen in equations (2) and (4) are equally considering the influence of porosity and particle size, differ in the values of constants and in a different way of accounting for the influence of particle shape on the amount of hydraulic resistance of the porous layer.

In the equation (2) there are the influence of particle shape is taken into account using the shape factor (coefficient). This coefficient is absent in the formula (4) and the influence of the particle shape is taken into account by the Kozeny-Carman constant " $K$ " in a complex composition with other factors that are not explicitly taken into account. Constant Kozeny-Pocket in the equation (4), in contrast to the constant in the equation (2) is variable and its value depending on the particle shape, the particle size distribution, the method of laying particles and the range of variation of porosity of the granular layer is determined in accordance with the recommendations outlined in the paper [76].

\section{Conclusions}

The results of processing a large array of the most reliable experimental data from various authors to determine the constant " $K$ " for granular layers consisting of particles of different geometric shapes are presented in the form of tables and extensive text material. Recommended values of the constant " $K$ " for some types of granular porous media are also specified. Thus, for a monodisperse layer of spherical particles in the range of porosity values $\varepsilon=0.38-0.41$, the constant values can be within the range $K=4.2-4$. 8 with its most reliable value $K$ equal to 4.55 . For a monodisperse layer of regular non-spherical particles (cubes, cylinders, prisms, disks) and shaped attachments (Raschig rings, Berl saddles, Lessing rings, steel springs), the values of the constant $K$ do not depend much on the shape of the particles and attachments, and in the porosity range $\varepsilon=0.33-0.4$ in most cases is within $K=4.6-4.8$. For a monodisperse layer of irregular-shaped particles, such as rounded particles with a smooth surface $K=4.8$. For rounded and cylindrical particles with a rough surface (activated carbon, sorbents, catalysts) and particles with a sharply irregular shape (crushed stone, crushed coal, catalysts for the synthesis of ammonia), the most likely value is the constant $K=5$. If a more precise value of the constant $K$ is required for performing calculations, then it should be determined experimentally in accordance with the recommendations set out in the paper [76].

There is no such amount of detailed information and recommendations for determining the particle shape factor (coefficient) for equation (2), which makes it very difficult to use it for practical calculations. In this regard, it should be considered that equation (4) is more preferable for practical use. 
In the well-known Ergun equation, the Kozeny-Carman equation (2) is used to determine the hydraulic resistance of a granular porous layer under nonlinear filtration conditions (figure 1). Obviously, because of the above, replacing this equation with the Kozeny-Carman equation in the form (4) will increase the accuracy of calculations performed using the Ergun equation. The generalized modified Ergun equation is written as

$$
\frac{\Delta P}{H}=K \frac{\sigma^{2}}{\varepsilon^{3}} \mu v_{\phi}+\zeta \rho v_{\phi},
$$

where $\zeta$ is the ripple coefficient that takes into account the structure of the porous layer and the contribution of the inertial component of the filtration flow structure.

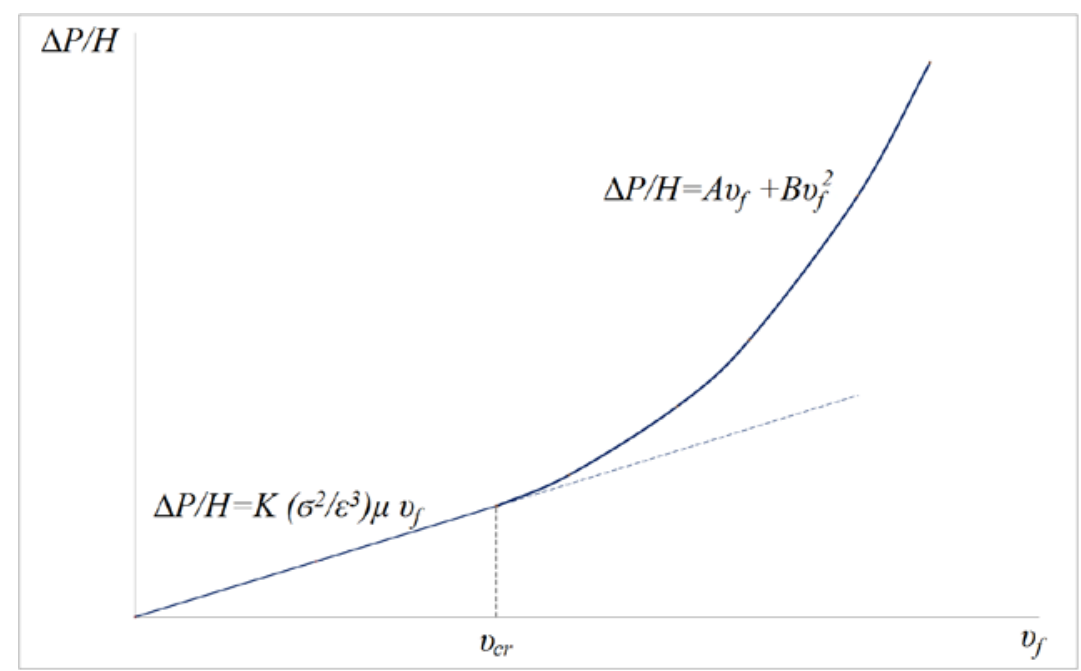

Fig. 1. The filtration curve with selected mode sections of laminar (linear) and transient (nonlinear) filtration.

The dependence (3) can be used to determine the hydraulic resistance of a porous layer consisting of a fibrous, mesh, sponge, or other porous non-granular material, but there is no information about the value of the Kozeny-Carman constant.

This work was supported by a grant from the President of the Russian Federation (MK-1287.2020.8) «Modelling of control processes in mass transfer environmental and petroleum processing equipment»

\section{References}

1. B.G. Pokusaev, D.A. Kazenin, S.P. Karlov, Yu.N. Skochilova, Areas of influence of an impurity source in filtration flows, Ecology and Industry of Russia, 4, pp. 41-43 (2008)

2. A.A. Sheldaisov-Meshcheryakov, P.S. Solmanov, N.M. Maximov, A.V. Mozhaev, D.I. Ishutenko, P.A. Nikul'shin, A.A. Pimerzin, Influence of the Pore Structure of a Catalyst for Demetallization of Petroleum Feedstock on the Process Results, Russian Journal of Applied Chemistry, 92, 10, pp. 1392-1398 (2019)

3. E.V. Shiryaeva, Yu.V. Gutin, A.A. Aksenov, Determination of filtration and dewatering parameters of sediments in industrial filters, Chemical and Petroleum Engineering, 44(11-12), pp. 611-621 (2008)

4. E.N. Dyachenko, N.N. Dyachenko, Numerical modeling of filtration of liquid through layer of bulk filter, Theoretical Foundations of Chemical Engineering, 47(3), pp. 262- 
265 (2013)

5. F.G. Akhmadiev, I.G. Bekbulatov, M.I. Farakhov, C.K. Isyanov, Mathematical modeling of filtering process of two-phase suspensions in tubular filters under nonisothermal conditions, Theoretical Foundations of Chemical Engineering, 50(1), pp. 41-51 (2016)

6. B.G. Pokusaev, E.A. Tairov, P.V. Khan, D.P. Khramtsov, Numerical and Analytical Approaches to Modeling Critical Two-Phase Flow with Granular Layer , Journal of Engineering Thermophysics, 27(1), pp. 20-29 (2018)

7. D.P. Khramtsov, A.V. Vyazmin, B.G. Pokusaev, S.P. Karlov, D.A. Nekrasov, Numerical simulation of slug flow mass transfer in the pipe with granular layer, Chemical Engineering Transactions, 52, pp. 1033-1038 (2016)

8. O.M. Sokovnin, S.N. Zagoskin, Kinetics of sorption of particles on granular filter, Theoretical Foundations of Chemical Engineering, 38(4), pp. 399-403 (2004)

9. A. Dmitriev, I. Madyshev, O. Dmitrieva, Experimental Study of Hydraulic and Heat and Mass Transfer Parameters of Inclined-corrugated Contact Elements of Cooling Tower Sprinkler, Ecology and Industry of Russia, 24(1), pp. 4-8 (2020)

10. A.B. Golovanchikov, V.A. Balashov, N.A. Merentsov, The filtration equation for packing material, Chem. and Pet. Eng., 53, pp. 10-13 (2017)

11. N.A. Merentsov, V.A. Balashov, D.Y. Bunin, V.N. Lebedev, A.V. Persidskiy, M.V. Topilin, Method for experimental data processing in the sphere of hydrodynamics of packed heat and mass exchange apparatuses, MATEC Web of Conf., 243, 5 (2018)

12. E.V. Shiryaeva, Y.V. Gutin, Methods of selecting primary and auxiliary equipment for industrial vacuum-filtration plants, Chemical and Petroleum Engineering, 46(5), pp. 298-304 (2010)

13. I.N. Madyshev, A.I. Khafizova, O.S. Dmitrieva, The study of gas-liquid flow dynamics in the inclined-corrugated elements of cooling tower filler unit, E3S Web of Conf., 126, 00031 (2019)

14. N.A. Merentsov, A.V. Persidskiy, M.V. Topilin, V.N. Lebedev, V.A. Balashov, A.B. Golovanchikov, Journal of Phys.: Conf. Ser., 1278, 012024 (2019)

15. A.B. Golovanchikov, N.A. Merentsov, M.V. Topilin, A.V. Persidskiy, IOP Conf. Ser.: Earth and Environmental Science, 288, 012089 (2019)

16. N. Merentsov, A. Persidskiy, M.Topilin, A. Golovanchikov, Sectional automatic adjustment of catalyst layers in gas and liquid phase reactors, MATEC Web of Conf., 298, 00030 (2019)

17. N.A. Merentsov, A.V. Persidskiy, V.V. Groshev, V.A. Kozlovtsev, A.B. Golovanchikov, Journal of Phys.: Conf. Ser., 1399,044041 (2019)

18. A. Fomenko, L. Sokolov, Sorption Removal of Oil Products from Waste Water, Ecology and Industry of Russia, 19(5), pp. 8-12 (2015)

19. E. Dremicheva, Use of Agricultural Waste for Wastewater Treatment of Industrial Enterprises, Ecology and Industry of Russia, 23(4), pp. 16-19 (2019)

20. A. Prolejchik, I. Gaponenkov, O. Fedorova, Extraction of Heavy Metal Ions from Inorganic Wastewater, Ecology and Industry of Russia, 22(3), pp. 35-39 (2018)

21. L.A. Nikolaeva, M.A. Golubchikov, A.R. Minneyarova, Research on the Mechanism and Kinetics of Oil-Product Adsorption from Industrial Wastewater by a Modified Hydrophobic Carbonate Sludge, Chemical and Petroleum Engineering, 53(11-12), pp. 806-813 (2018)

22. L.I. Sokolov, Use of wastes of grinding industry for cleaning of chromium containing effluent waters, World Applied Sciences Journal, 22(5), pp. 690-696 (2013)

23. N.A. Merentsov, S.A. Bokhan, V.N. Lebedev, A.V. Persidskiy, V.A. Balashov, System for centralised collection, recycling and removal of waste pickling and galvanic solutions and sludge, Materials Science Forum, 927, pp. 183-189 (2018) 
24. R. Alexandrov, D. Feklistov, N. Laguntsov, I. Kurchatov, Mobile Installation of Water Treatment in the Aftermath of Emergency Situations, Ecology and Industry of Russia, 23(1), pp. 4-10 (2019)

25. E. Dremicheva, Use of Agricultural Waste for Wastewater Treatment of Industrial Enterprises, Ecology and Industry of Russia, 23(4), pp. 16-19 (2019)

26. E.S. Dremicheva, A.G. Laptev, Modeling the Process of Sorption for the Purification of Waste Water from Petroleum Products and Heavy Metals, Theoretical Foundations of Chemical Engineering, 53(3), pp. 355-363 (2019)

27. E.S. Dremicheva, E.V. Shamsutdinov, Intensification of sedimentation treatment of wastewater from oil products, Water and Ecology, 1, pp. 3-8 (2018)

28. L.A. Nikolaeva, R.Y. Iskhakova, Integrated Wastewater Treatment for a GRES, Thermal Engineering, 66(8), pp. 587-592 (2019)

29. L.A. Nikolaeva, R.Ya. Iskhakova, Adsorption of industrial wastewater from oil products with application of mathematical modeling, IOP Conference Series: Earth and Environmental Science, 288(1),012017 (2019)

30. L.A. Nikolaeva, D.A. Khamzina, Purification of water sources from oil contamination by hydrophobic carbonate sludge, IOP Conference Series: Earth and Environmental Science, 288(1),012018 2019

31. L.A. Nikolaeva, R.Y. Iskhakova, Mathematical Modeling of Wastewater Treatment by Adsorption of Petroleum Products, Chemical and Petroleum Engineering, 55(1-2), pp. 68-75 (2019)

32. N. Merentsov, A. Persidskiy, M. Topilin, Description of the process and packing materials for pulse liquid extraction, Materials Today: Proceedings, 19(5), pp. 19081912 (2019)

33. N. Merentsov, A. Persidskiy, V. Lebedev, Automatic parameter adjustment system for packing materials and control of flow modes in mass exchange columns, Materials Today: Proceedings, 19(5), pp. 1899-1903 (2019)

34. N. Merentsov, A. Persidskiy, V. Lebedev, M. Topilin, A. Golovanchikov, Modelling and Calculation of Industrial Absorber Equipped with Adjustable Sectioned Mass Exchange Packing, Advances in Intelligent Systems and Computing, 983, pp. 560-573 (2019)

35. L.A. Nikolaeva, A.R. Minneyarova, Adsorption Treatment of Reverse-Osmosis Concentrate from Water-Treatment Units at Thermal Power Stations, Thermal Engineering, 66(5), pp. 372-376 (2019)

36. L.A. Nikolaeva, M.A. Golubchikov, A.R. Minneyarova, Research on the Mechanism and Kinetics of Oil-Product Adsorption from Industrial Wastewater by a Modified Hydrophobic Carbonate Sludge, Chemical and Petroleum Engineering, 53(11-12), pp. 806-813 (2018)

37. L.A. Nikolaeva, M.A. Golubchikov, Study of the sorption of oil products of power station wastewater modified with a TPP illuminator slurry, Thermal Engineering, 59(5), pp. 404-407 (2012)

38. L.A. Nikolaeva, R.Ya. Nedzvetskaya, Purification of effluent waters from industrial enterprises using a biosorption technology, Thermal Engineering, 59(3), pp. 258260 (2012)

39. N.A. Merentsov, V.A. Balashov, S.A. Bokhan, E.E. Nefed'eva, D.A. Tezikov, V.V. Groshev, Modeling and calculation of flow filter, IOP Conf. Ser.: Earth and Envir. Sci., 224, 012041 (2019)

40. A. Kutergin, T. Nedobukh, The Use of Aluminosilicate Sorbent for the Purification of Natural Waters from Heavy Metals, Ecology and Industry of Russia, 24(3), pp. 19-23. (2020)

41. P.A. Krivosheev, L.F. Komarova, M.A. Poletaeva, I.A. Lebedev, S.S. Lavrinenko, 
Wastewater treatment with new activated charcoals to remove butano, Russian Journal of Applied Chemistry, 77(9), pp. 1515-1517 (2004)

42. V. Smirnov, V. Dyrdin, T. Kim, A. Manakov, Effect of the hydrate saturation of the pores of coal bed on the gradient of gas pressure and the rise of outburst danger, E3S Web of Conferences, 105,01044 (2019)

43. T. Kim, V. Dyrdin, V. Smirnov, V. Nesterov, Gas hydrates in coal seams and their impact on gas-dynamic processes in underground mining, E3S Web of Conferences, 15, 01022 (2017)

44. N.A. Merentsov, A.B. Golovanchikov, M.V. Topilin, A.V. Persidskiy, D.A. Tezikov, Journal of Phys.: Conf. Ser., 1399, 055028 (2019)

45. A. Golovanchikov, N. Merentsov, Modelling of Absorption Process in a Column with Diffused Flow Structure in Liquid Phase, Advances in Intelligent Systems and Computing, 983, pp. 635-644 (2019)

46. A. Golovanchikov, N. Merentsov, Ion Exchange in Continuous Apparatus with Diffused Flow Structure in Liquid, Advances in Intelligent Systems and Computing, 983, pp. 645-652 (2019)

47. A.B. Golovanchikov, N.A. Merentsov, M.V. Topilin, Journal of Phys.: Conf. Ser., 1278, 012023 (2019)

48. A. Prolejchik, I. Gaponenkov, O. Fedorova, Extraction of Heavy Metal Ions from Inorganic Wastewater, Ecology and Industry of Russia, 22(3), pp. 35-39 (2018)

49. A.I. Fomenko, L.I. Sokolov, Study of Sorption Properties of Bog Ores for Extraction of Manganese and Iron Ions from Ground Water, Russian Journal of Applied Chemistry, 92(2), pp. 288-294 (2019)

50. N.G. Rachkova, I.I. Shuktomova, Sorption of uranium, radium, and thorium by analcym-containing rock and sorbents based on plant tissue, Russian Journal of Applied Chemistry, 83(4), pp. 620-624 (2010)

51. T.A. Zaporozhskikh, Ya.K. Tret'yakova, V.A. Grabel'nykh, N.V. Russavskaya, V.Yu. Vshivtsev, E.P. Levanova, E.N. Sukhomazova, I.V. Korabel, N.A. Korchevin, Granulated sulfur-containing sorbents for recovery of heavy metal ions from aqueous solutions, Russian Journal of Applied Chemistry, 81(5), pp. 886-888 (2008)

52. A.I. Fomenko, L.I. Sokolov, Sorption properties of fly ash microspheres of thermal power plants, Ecology and Industry of Russia, 23(1), p. 50-54 (2019)

53. V.G. Smirnov, V.V. Dyrdin, A.Y. Manakov, N.I. Fedorova, N.V. Shikina, Z.R. Ismagilov, Physicochemical and Sorption Properties of Natural Coal Samples with Various Degrees of Metamorphism, Russian Journal of Applied Chemistry, 92(10), pp. 1410-1421 (2019)

54. A.I. Fomenko, L.I. Sokolov, Ash of incineration plants as industrial resource for extracting rare earth elements, Ecology and Industry of Russia, 21(12), pp. 28-31 (2017)

55. N. Merentsov, A. Persidskiy, V. Lebedev, A. Golovanchikov, Automatic Control of Operating Modes of Packed Apparatus for Selective Gas Emissions Cleaning, Ecology and Industry of Russia, 24(2), pp. 10-16 (2020)

56. N. Merentsov, A. Persidskiy, V. Lebedev, A. Golovanchikov, The use of industrial wastes from machine-building enterprises as packing materials for small-sized absorbers for gas emissions purification, MATEC Web of Conf., 298, 00031 (2019)

57. A.I. Fomenko, L.I. Sokolov, A study of sorption of phosphate ions from aqueous solutions by wood ash, Russian Journal of Applied Chemistry, 88(4), pp. 652-656 (2015)

58. E.S. Dremicheva, Studying the sorption kinetics on peat ions of iron(III) and copper(II) from wastewater, Moscow University Chemistry Bulletin, 72(4), pp. 196199 (2017) 
59. L.A. Nikolaeva, É.G. Khamitova, The Use of Energy Industry Waste as Sorption Material in the Purification of Reverse Osmosis Concentrate, Chemical and Petroleum Engineering, 55(5-6), pp. 427-432 (2019)

60. L.A. Nikolaeva, É.R. Zainullina, A.K. Al'-Okbi, Adsorption Drying of Natural Gas by Carbonate Sludge, Chemical and Petroleum Engineering, 54(11-12), pp. 919-925 (2019)

61. L.A. Nikolaeva, A.N.Khusnutdinov, A Study of the Absorption of Nitrogen Oxides from the Boiler Flue Gases, Thermal Engineering, 65(8), pp. 575-579 (2018)

62. L.A. Nikolaeva, A.N. Khusnutdinov, Purification of gas emissions of chemical industry enterprises by carbonaceous cutting, Ecology and Industry of Russia, 22(8), pp. 14-18 (2018)

63. L.A. Nikolaeva, Research of sorption processes using chemical water purification sludge for nitrogen and sulfur oxides contained in smoke gases emitted from a thermal power station, Thermal Engineering (English translation of Teploenergetika), 60(4), pp. 244-247 (2013)

64. V. Smirnov, V. Dyrdin, T. Kim, A. Manakov, A. Khoreshok, Experimental Study of Methane Hydrates in Coal, E3S Web of Conferences, 15,01020 (2017)

65. V.G. Smirnov, V.V.Dyrdin, A.Y. Manakov, N.V. Shikina, Z.R. Ismagilov, Physicochemical and Sorption Properties of Natural Coal Samples with Various Degrees of Metamorphism, Russian Journal of Applied Chemistry, 92(10), pp. 14101421 (2019)

66. A. Dmitriev, I. Madyshev, O. Dmitrieva, Cleaning of Industrial Gases from Aerosol Particles in Apparatus with Jet-Film Interaction of Phases, Ecology and Industry of Russia, 22(6), pp.10-14 (2018)

67. A.B. Golovanchikov, N.A. Merentsov, V.A. Balashov, Modeling and analysis of a mechanical-draft cooling tower with wire packing and drip irrigation, Chem. and Pet. Eng. 48, pp. 595-601 (2013). doi: 10.1007/s10556-013-9663-2

68. N.A. Merentsov, A.V. Persidskiy, V.N. Lebedev, Use of Wastes from Metalworking Machining for Packings in Contact Heat-and-Mass Exchange Devices, Proceedings of the 5th International Conference on Industrial Engineering (ICIE 2019), Lecture Notes in Mechanical Engineering, II, pp. 1443-1454 (2020)

69. N. Merentsov, A. Persidskiy, V. Lebedev, N. Prokhorenko, A. Golovanchikov, Heat and Mass Exchange Packing for Desinfection of Circulation Water in Electric Field, Advances in Intelligent Systems and Computing, 983, 547-559 (2019)

70. N.A. Merentsov, V.N. Lebedev, A.V. Persidskiy, A.B. Golovanchikov, Journal of Phys.: Conf. Ser., 1515, 022004 (2020)

71. N.A. Merentsov, V.N. Lebedev, A.V. Persidskiy, V.A. Balashov, IOP Conf. Ser.: Earth and Environmental Science, 288, 012106 (2019)

72. N.A. Merentsov, V.N. Lebedev, A.B. Golovanchikov, V.A. Balashov, E.E. Nefed'Eva, IOP Conf. Ser: Earth and Environmental Science, 115, 012017 (2018)

73. A.V. Persidskiy, N.A. Merentsov, V.N. Lebedev, A.B. Golovanchikov, IOP Conf. Ser.: Earth and Environmental Science, 288, 012110 (2019)

74. A.G. Kasatkin, The main processes and devices based on technology (Alliance, Moscow, 2004)

75. P.G. Romankov, M.I. Kurochkina, Hydromechanical processes of chemical technology (Chemistry, Leningrad, 1982)

76. M.E. Aerov, O.M. Todes, D.A. Narinsky, Devices with a stationary granular layer. Hydraulic and thermal fundamentals of work (Chemistry, Leningrad, 1979) 